Metal-Catalyzed

Asymmetric

Synthesis and

Stereoselective

Reactions

\title{
Asymmetric Cyclopropanation Using Dimethyl Diazomalonate
}

Key words

chiral dienes

cyclopropanation

rhodium<smiles>[R]C=C[O+]</smiles>

$\mathrm{RhCl}\left(\text { ligand }^{*}\right)_{2}$ (2 mol\%) $\underset{\mathrm{PhMe}, 40^{\circ} \mathrm{C}, 48-72 \mathrm{~h}}{\stackrel{\mathrm{NaBAr}_{4}}{(} \text { (4 mol\%) }}$<smiles>[R]C1CC1(C(C)=O)C(C)=O</smiles>

9 examples up to $96 \%$ yield up to $90 \%$ ee

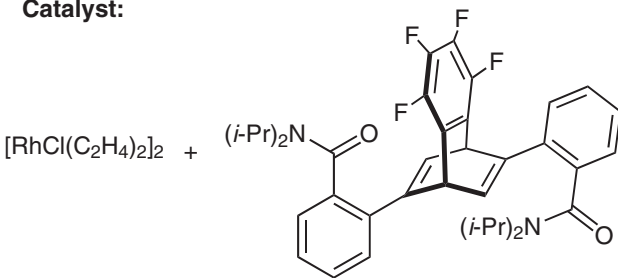

ligand

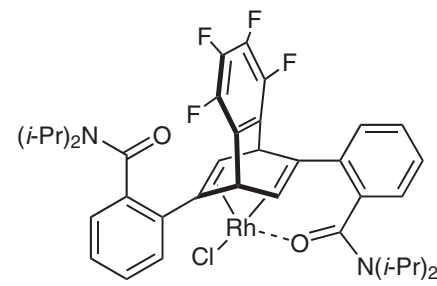

catalyst

Selected examples:<smiles></smiles>

$86 \%$ yield $89 \%$ ee

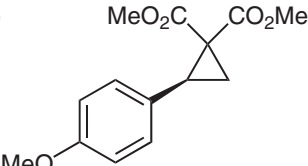

$96 \%$ yield $80 \%$ ee
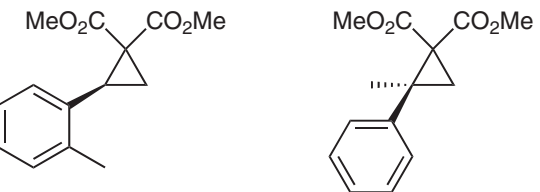

$78 \%$ yield $88 \%$ ee
Significance: Many well-developed dirhodium(II) carboxamidates and carboxylates exist for highly enantioselective cyclopropanations of alkenes with diazo compounds (see Review below). Due to often low reactivity and enantioselectivity no highly asymmetric cyclopropanation using diazomalonates exists. The authors discovered that chiral cyclopropane gem-diesters can be prepared in good yields and enantioselectivies by using a cationic chiral rhodium-diene complex.

Review: H. Pellissier Tetrahedron 2008, 64, 70417095.
Comment: The authors screened a number of existing ligands for the title transformation, but an effective catalyst was not found. By placing amide groups on the ortho position of their previously developed tetrafluorobenzobarrelene ligands, good yields and enantioselectivities were obtained. X-ray crystallographic analyses of the complexes show a coordination of one of the amide oxygens to rhodium in the neutral complex, and both amide oxygens coordinating in the in situ formed cationic species. This structural feature is proposed to be crucial for the high reactivity. 